\title{
Types of smartphone usage and relations with problematic smartphone behaviors: The role of content consumption vs. social smartphone use
}

\author{
Jon D. Elhai ${ }^{1,2}$, Brian J. Hall ${ }^{3,4}$, Jason C. Levine ${ }^{1,2}$, \& Robert D. Dvorak ${ }^{5}$ \\ ${ }^{1}$ Department of Psychology, University of Toledo, Toledo, OH, USA \\ ${ }^{2}$ Department of Psychiatry, University of Toledo, Toledo, OH, USA \\ ${ }^{3}$ Department of Psychology, University of Macau, Taipa, Macau (SAR), People's Republic of China \\ ${ }^{4}$ Department of Health, Behavior and Society, Johns Hopkins Bloomberg School of Public Health, Baltimore, MD, USA \\ ${ }^{5}$ Department of Psychology, University of Central Florida, Orlando, FL, USA
}

\begin{abstract}
Little previous research has clarified which types of smartphone use are related to problematic smartphone behaviors. We sampled 309 community participants online to understand the role of content consumption vs. social smartphone use in relation to specific problematic smartphone behaviors. Bivariate correlations indicated mostly significant relationships between problematic smartphone behaviors and both process and social usage but with stronger correlations for process usage. Regression analyses, controlling for age and gender, demonstrated that problematic smartphone-related overuse was significantly associated with process smartphone usage, and to a lesser extent - social usage. Positive anticipation problem behaviors were related to process and social usage. Daily life disturbances from a smartphone were inversely related to process and social usage. Results provide insight into the types of problem smartphone behaviors associated with specific uses and gratifications from a smartphone.
\end{abstract}

Keywords: Information technology; mobile phones; internet addiction; gratification; social networks

\section{Introduction}

Overuse or "addiction" to smartphones can have harmful physical health effects. For example, problematic smartphone use is related to traffic accidents (Cazzulino, Burke, Muller, Arbogast, \& Upperman, 2014; Thompson, Rivara, Ayyagari, \& Ebel, 2013), shoulder and neck problems (Shan et al., 2013; Xie, Szeto, Dai, \& Madeleine, 2016), sleep impairment (Demirci, Akgonul, \& Akpinar, 2015; Eyvazlou, Zarei, Rahimi, \& Abazari, 2016), academic problems (Seo, Park, Kim, \& Park, 2016), and poor physical fitness (Rebold, Sheehan, Dirlam, Maldonado, \& O'Donnell, 2016). Furthermore, problematic smartphone use is related to mental health problems such as anxiety and depression (reviewed in Elhai, Dvorak, Levine, \& Hall, 2017). However, little is known about the types of smartphone use implicated in problematic smartphone behaviors.

There are many uses and features for a smartphone. Smartphone technology, as well as internet technology in general, can be characterized by uses such as productivity enhancement (e.g., reminders and email), information seeking (e.g., web surfing, browsing the news), and social information and relationships (e.g., social media, messaging). Additional uses include diversion and relaxation (e.g., music), entertainment (e.g., gaming, movies), monetary compensation (e.g., locating consumer deals) and personal status (Dhir, Chen, \& Nieminen, 2015; Song, LaRose, Eastin, \& Lin, 2004; van Deursen, Bolle, Hegner, \& Kommers, 2015). 
Internet use has been classified under two primary categories: process use, and social use (Song et al., 2004). Van Deursen et al. (2015) extended this categorization to smartphone usage. Process usage primarily involves content-based consumption of media, such as browsing news websites, and viewing movies. On the other hand, social usage involves interacting with one's social network through social media interaction, and instant messaging. One study found that problematic smartphone use was related to process but not social usage (van Deursen et al., 2015), while another study found the opposite (Zhitomirsky-Geffet \& Blau, 2016). Other research has found that social usage was substantially more prevalent than process use among problematic smartphone users (Lee et al., 2014; Lopez-Fernandez, Honrubia-Serrano, Freixa-Blanxart, \& Gibson, 2014); a finding also revealed in problem internet users (Chou \& Hsiao, 2000; Yang \& Tung, 2007). Finally, another study revealed that problematic smartphone use was related to both process and social use, but the association was stronger for process use (Elhai, Levine, Dvorak, \& Hall, 2017). Importantly, we do not know the extent to which process and social smartphone use differentially relate to specific types of problematic smartphone use.

Studying process and social smartphone usage can be placed within the context of Uses and Gratifications Theory (UGT; Blumler \& Katz, 1974). UGT discusses which types of mass media are sought and consumed by people in order to satisfy personal needs (e.g., entertainment, social), and explanations for such individual decisions. In UGT, the types of media sought are assumed to be based on individual difference variables (Blumler, 1979). UGT is unique among other theories in assuming that users are active consumers of media (West \& Turner, 2007). UGT has been applied to understanding problematic internet use (e.g., Kim \& Haridakis, 2009; Song et al., 2004), and more recently to problematic smartphone use (Dhir et al., 2015; Elhai, Levine, et al., 2017; Park, Kim, Shon, \& Shim, 2013) by examining individual differences accounting for problematic use. Applying UGT within the context of problem smartphone use, individuals' problem smartphone behaviors may vary as a function of the particular types of smartphone uses they prefer (Park et al., 2013).

Kardefelt-Winther's (2014) recently-developed Compensatory Internet Use Theory (CIUT) could be viewed as an extension of UGT, in explaining variables that drive such use. Specifically, this theory attempts to understand the negative life events and stressors that motivate some people to use (or overuse) technology in order to alleviate negative emotion about such stressors. Thus, this theory does not focus on psychopathology as the direct cause of problematic internet use. Instead, it emphasizes negative life circumstances as the cause, and problematic internet use as the consequent, compensatory behavior aimed at regulating stressor-related negative emotion. Several studies thus far have found empirical support for this theory as related to the study of problematic smartphone use (Long et al., 2016; Wang, Wang, Gaskin, \& Wang, 2015; Zhitomirsky-Geffet \& Blau, 2016).

Within the context of UGT and CIUT, we aimed to examine process and social smartphone usage in relation to problematic smartphone use. Kwon et al. (2013), through latent variable modeling of the Smartphone Addiction Scale (SAS), empirically identified six types of problem smartphone use behaviors/symptoms. These behaviors and symptoms include "daily life disturbance" (work/academic functional impairment or health problems; 5 items), "positive anticipation" (excitement of alleviating stress with a smartphone, hedonic use; 8 items), and "withdrawal" symptoms when separated from one's phone (6 items). Also included are "cyberspace relationships" (preferred to offline relationships; 7 items), "overuse" (uncontrollable desire for smartphone use; 4 items), and tolerance (failed attempts to reduce use; 3 items). This symptom structure is very similar to that revealed in a revised version of the SAS, translated into Estonian (Rozgonjuk, Rosenvald, Janno, \& Täht, 2016). Many of these symptom dimensions (e.g., positive anticipation, withdrawal, tolerance, overuse, and life disturbance) map onto current models of drug and alcohol addiction (Robinson \& Berridge, 2000; Wise \& Koob, 2014).

In the present study, we used a community sample of adults recruited via the internet to examine symptom dimensions of problematic smartphone behavior most related to process smartphone usage, and social smartphone usage. We statistically controlled for age and gender in regression models as previous research indicates that younger individuals are more likely to engage in process and social smartphone use (van Deursen et al., 2015) and women engage in more social smartphone use than men do (van Deursen et al., 2015). Our overarching research question was: What is the relationship between the type of smartphone use (process and social) and the type of problematic smartphone use behavior? This study is unique in adding to the limited literature on the types of uses (process vs. social) associated with problematic smartphone use (Elhai, Levine, et al., 2017; Lopez-Fernandez et al., 2014; van Deursen et al., 2015; Zhitomirsky-Geffet \& Blau, 2016) by more 
precisely measuring multiple symptom dimensions of problem use. Examining types of smartphone use in relation to problematic use has important implications for advancing theoretical models such as UGT and CIUT, ultimately in gaining a better understanding of what drives problematic smartphone use.

Using UGT and CIUT, we hypothesized the following.

1. Higher levels of smartphone-related process and social usage should be associated with more problematic smartphone behaviors (Elhai, Levine, et al., 2017; Kim \& Haridakis, 2009; Wang, Tchernev, \& Solloway, 2012). Specifically, problematic overuse and daily disturbance behaviors from the SAS should be associated with both process and social use (Kim \& Haridakis, 2009).

2. The SAS' problematic positive anticipation subscale would be most associated with social usage. This hypothesis is derived from research finding that an important pathway toward problematic smartphone use involves habitual phone-checking behaviors for social notifications (Lee et al., 2014; Oulasvirta, Rattenbury, Ma, \& Raita, 2012). Social notifications result in instant gratification (involved in positive anticipation), which drives more phone usage (theoretically, social usage), including problematic use (Oulasvirta et al., 2012).

\section{Method}

\section{Procedure and Participants}

We recruited 322 participants in February 2016 from the Amazon Mechanical Turk (Mturk) labor marketplace, which is often used in social science research (Steelman, Hammer, \& Limayem, 2014). We advertised the study as a 15-20-minute survey on mobile device and internet use, offering 75 cents compensation through Amazon Payments. Through online screening, we targeted only North American, English speaking adults (through credit check verification, only individuals age 18 or older can obtain an Mturk account). We used Mturk in order to maximize the proportion of avid technology and smartphone users.

Participants were routed to an online consent statement using the PsychData web survey platform, and those agreeing to participate were routed to a web survey including instruments described below. We removed 13 participants from analyses who indicated non-North American residence $(n=4)$, did not provide a unique Mturk worker identification number $(n=5)$, or quit the survey soon after starting it $(n=4)$, resulting in 309 participants. No subjects needed to be removed for not owning a smartphone.

A slight majority of participants were men ( $n=165,53.6 \%)$. The majority reported a Caucasian racial background ( $n=253,82.1 \%)$, with additional race and ethnic representation by 28 Asians (9.1\%), 23 African Americans (7.5\%), and 16 Hispanic individuals (5.3\%) (these categories were not mutually exclusive). Age averaged 33.15 years (SD = 10.21). A slight majority held a Bachelor's degree $(n=170,55.2 \%)$, or at least some (but not completed) college education ( $n=104,33.8 \%)$; less education was reported by the remaining 35 participants (11.3\%). Full- or parttime employment was endorsed by most participants ( $n=196,44.1 \%, n=56,18.3 \%$, respectively). Slightly more than one-third of participants reported being currently married $(n=114,37.3 \%)$.

\section{Measures}

Participants were administered a battery of online self-report measures. Instruments relevant to this study are described here. First, we assessed demographic characteristics, such as age and gender.

Process vs. Social Smartphone Usage. We assessed two major motivations of smartphone usage - process (e.g., news consumption, entertainment) and social (e.g., communication, social networking), a distinction in technology use found in the literature (Song et al., 2004). We measured seven process and five social usage items using a 5 -point Likert-type scale, ranging from " $1=$ Strongly disagree" to " $5=$ Strongly agree," from the measure reported in van Deursen et al. (2015). van Deursen et al. (2015) reported alpha coefficients of .89 for process and .73 for social usage. We found alphas of .85 and .77 , respectively. 
Smartphone Addiction Scale (SAS). We used Kwon et al.'s (2013) SAS to measure problem smartphone use. The SAS has 33 items, with Likert item responses from " 1 = Strongly disagree" to "6 = Strongly agree." The SAS was validated against other measures of problematic smartphone use (Kwon et al., 2013). Kwon et al. (2013) reported coefficient alphas ranging from .83 for the tolerance subscale to .91 for positive anticipation. We found alphas ranging from .78 for overuse to .87 for both daily life disturbance and cyberspace relationships.

\section{Analyses}

We estimated missing item-level data within the scales using maximum likelihood procedures, with the Mplus 7 software. Subsequently, item-level data were used to compute scale scores. Scale scores were all normally distributed, based on skewness and kurtosis values; the highest values in absolute size were 1.18 for skewness (SAS' Daily Life Disturbances subscale), and 2.00 for kurtosis (social smartphone use scale). We report descriptive statistics for the scale scores (Table 1). Pearson correlations are provided for relations between the SAS subscales and three outcome variables, including t-tests for dependent correlations (Table 2).

Table 1. Descriptive Statistics and Correlations for the SAS Subscales and Process Usage and Social Usage.

\begin{tabular}{lccccccccccc}
\hline Variable & $\boldsymbol{M}$ & SD & Min & Max & $\mathbf{1}$ & $\mathbf{2}$ & $\mathbf{3}$ & $\mathbf{4}$ & $\mathbf{5}$ & $\mathbf{6}$ & $\mathbf{7}$ \\
\hline 1. Daily Life Disturbance & 9.06 & 4.83 & 5 & 25 & & & & & & \\
2. Positive Anticipation & 25.96 & 7.88 & 8 & 48 & $.35^{*}$ & & & & & \\
3. Withdrawal & 16.20 & 6.59 & 6 & 35 & $.48^{*}$ & $.67^{*}$ & & & & \\
4. Cyberspace Relationships & 17.00 & 7.67 & 7 & 42 & $.55^{*}$ & $.68^{*}$ & $.74^{*}$ & & & \\
5. Overuse & 12.91 & 5.10 & 4 & 24 & $.41^{*}$ & $.54^{*}$ & $.70^{*}$ & $.63^{*}$ & & \\
6. Tolerance & 7.36 & 3.84 & 3 & 18 & $.57^{*}$ & $.41^{*}$ & $.65^{*}$ & $.65^{*}$ & $.69^{*}$ & \\
7. Process Use & 25.80 & 4.98 & 7 & 35 & .05 & $.50^{*}$ & $.32^{*}$ & $.34^{*}$ & $.38^{*}$ & $.22^{*}$ & \\
8. Social Use & 20.34 & 3.43 & 5 & 25 & $.17^{*}$ & $.27^{*}$ & $.15^{*}$ & .14 & $.23^{*}$ & .04 & $.58^{*}$ \\
\hline
\end{tabular}

Note: * $p<.01$

Table 2. Correlations for SAS Subscales with Process Usage and Social Usage, and Tests of Differences Between Correlations.

\begin{tabular}{lccc}
\hline Variable & $\begin{array}{l}\text { Correlation with } \\
\text { Process Usage }\end{array}$ & $\begin{array}{l}\text { Correlation with } \\
\text { Social Usage }\end{array}$ & $\begin{array}{l}\text { Difference Between This Row's } \\
\text { Correlations } \\
\mathbf{t ( 3 0 6 )}\end{array}$ \\
\hline Daily Life Disturbance & .05 & $-.17^{*}$ & $4.36^{*}$ \\
Positive Anticipation & $.50^{*}$ & $.27^{*}$ & $5.07^{*}$ \\
Withdrawal & $.32^{*}$ & $.15^{*}$ & $3.44^{*}$ \\
Cyberspace Relationships & $.34^{*}$ & $.14^{*}$ & $4.08^{*}$ \\
Overuse & $.38^{*}$ & $.23^{*}$ & $3.10^{*}$ \\
Tolerance & $.22^{*}$ & .04 & $3.56^{*}$ \\
\hline
\end{tabular}

Note: SAS $=$ Smartphone Addiction Scale. ${ }^{*} p<.01$

Next, we conducted two sequential linear regression analyses - one for each of the following dependent variables: a) process usage, and b) social usage. In step 1 of each analysis, we controlled for age and gender. In step 2, we tested the additive effect of the six SAS subscales as predictor variables.

We should note that prior research often has assessed smartphone use as the predictor variable(s) and problematic use as the dependent variable(s) (Elhai, Levine, et al., 2017; Park et al., 2013; van Deursen et al., 2015). In the present paper, we used the reverse ordering of variables. We used this ordering because specifying the six SAS subscales as predictors rather than dependent variables facilitates interpretation of the findings with so many variables. Of course, our models are not causal, as our data were cross-sectional; thus the ordering need not be unidirectional. 


\section{Results}

Table 1 depicts descriptive statistics for the scale scores analyzed, along with zero-order Pearson correlations for the SAS subscales and process and usage variables. We found that process and social usage were correlated $(r=$ $.58, p<.001$ ). Based on $t$-tests for dependent correlations (Table 2), all SAS subscales were significantly more related to process usage as compared to social usage.

Table 3 displays linear regression results for the SAS subscales in accounting for variance in process usage scores. After controlling for age and gender, the SAS subscales were significant, $F(8,300)=17.90, p<.001$, accounting for $31 \%$ of the variance in process use. Adjusting for other predictor variables, positive anticipation and overuse were positively related, and daily life disturbance was negatively related to process usage.

Table 3. Multiple Regression Results for Process Usage: Final Model.

\begin{tabular}{|c|c|c|c|c|c|}
\hline Predictor of Process Usage (Added) & $\beta$ & $B$ & SE B & $t$ & $\Delta R^{2}$ \\
\hline (Step 1) & & & & & .02 \\
\hline Age & -.11 & -.05 & .02 & -2.15 & \\
\hline Gender ( 1 =men, $2=$ women) & .12 & 1.14 & .49 & 2.33 & \\
\hline (Step 2) & & & & & .31 \\
\hline Daily Life Disturbance & -.19 & -.20 & .06 & $-3.13^{*}$ & \\
\hline Positive Anticipation & .49 & .31 & .05 & $6.87 *$ & \\
\hline Withdrawal & -.11 & -.08 & .06 & -1.32 & \\
\hline Cyberspace Relationships & .06 & .04 & .06 & .68 & \\
\hline Overuse & .24 & .23 & .07 & $3.13^{*}$ & \\
\hline Tolerance & -.02 & -.02 & .10 & -.23 & \\
\hline
\end{tabular}

Note: * $p<.01$

Table 4 displays linear regression results for the SAS subscales accounting for variance in social usage scores. After controlling for age and gender, the SAS subscales were significant, $F(8,300)=104.49, p<.001$, accounting for $19 \%$ of variance in social use. Adjusting for other variables, positive anticipation and overuse were positively related, and daily life disturbance was negatively related to social usage.

Table 4. Multiple Regression Results for Social Usage: Final Model.

\begin{tabular}{lccccc}
\hline Predictor of Social Usage (Added) & $\boldsymbol{B}$ & $\boldsymbol{B}$ & $\boldsymbol{S E}$ & $\boldsymbol{t}$ & $\boldsymbol{\Delta R}^{\mathbf{2}}$ \\
\hline (Step 1) & & & & & .04 \\
Age & -.13 & -.04 & .02 & -2.42 \\
Gender (1=men, 2=women) & .18 & 1.23 & .36 & $3.39^{*}$ \\
(Step 2) & & & & & .19 \\
Daily Life Disturbance & -.34 & -.24 & .05 & $-5.21^{*}$ & \\
Positive Anticipation & .28 & .12 & .03 & $3.70^{*}$ \\
Withdrawal & -.06 & -.03 & .05 & -.70 \\
Cyberspace Relationships & .09 & .04 & .04 & .99 \\
Overuse & .25 & .17 & .05 & $3.09 *$ \\
Tolerance & -.08 & -.07 & .07 & -.99 \\
\hline
\end{tabular}

Note: * $p<.01$ 


\section{Discussion}

In the present study, we found significant (unadjusted) bivariate relations between most problematic smartphone use behaviors and process and social smartphone usage, with significantly larger relationships for process usage. In regression models, positive relationships with process use - and to a lesser extent, social usage - were revealed for overuse behaviors. Positive relationships with process and social usage were discovered for positive anticipation. Results revealed an inverse relationship for process and social usage with daily disturbance. These results help clarify the types of problem smartphone behaviors associated with various smartphone uses

We found, using regression models, that after adjusting for other variables, problematic smartphone-related positive anticipation and overuse were both related to process and social smartphone usage - though effects were smaller for social use. We hypothesized such a relationship in predicting social use (Kim \& Haridakis, 2009), but we did not expect positive anticipation behaviors related to process use. In fact, some studies find that problematic smartphone use is more related to social use (Lopez-Fernandez et al., 2014; Zhitomirsky-Geffet \& Blau, 2016), while others find more support for process use (Elhai, Levine, et al., 2017; van Deursen et al., 2015). Based on results of the present study, perhaps in addition to social networking and message notifications that drive problematic smartphone use (Lee et al., 2014; Oulasvirta et al., 2012), non-social gratifications may drive overuse as well (Elhai, Levine, et al., 2017; van Deursen et al., 2015). This finding supports CIUT (KardefeltWinther, 2014), in which it would be expected that the hedonic use of a smartphone (consistent with process use) could be a means to compensate for negative emotion. It is possible that the gratifications from process smartphone use, such as pleasure derived from seeing anticipated news stories, or buying a long-awaited product from one's phone, can lead to greater, or problematic smartphone use. For instance, research demonstrates that problematic internet use (but not smartphone-specific) is strongly related to compulsive online shopping (Kuss, Griffiths, \& Binder, 2013) and online gaming (Gunuc, 2015; Kuss et al., 2013), both of which involve more process-oriented than social-oriented gratification. However, we must note that a particular smartphone feature may not be exclusively a process- or social-related activity. For instance, online gaming, although more process-oriented, can have a strong social component such as in massive multiplayer gaming (Trepte, Reinecke, \& Juechems, 2012).

We discovered that daily life disturbances were inversely related to process and social usage, however. One explanation is that people enjoy engaging in more process and social smartphone usage, and thus it does not feel like one's smartphone interferes with daily life. This finding also fits with CIUT in that people may compensate for negative emotion by engaging in process and/or social smartphone use, and such smartphone engagement may help alleviate negative mood (Kardefelt-Winther, 2014). In fact, people may feel as though greater process and social use (to an extent) helps them in daily life because of the productivity and time-saving features of a smartphone. After all, smartphones have been found to increase productivity in the workplace (e.g., Kalkbrenner \& McCampbell, 2011; Ozdalga, Ozdalga, \& Ahuja, 2012), enhance school learning (GodwinJones, 2011), and building social capital (Park, Han, \& Kaid, 2012). It is possible that this inverse relationship may be a function of statistical suppression within the context of the regression analysis. However, even in our bivariate analyses, social usage was inversely related to daily life disturbance.

Also noteworthy to mention, but not part of our primary research questions, were effects for the age and gender covariates in relation to process and social smartphone usage. Past research has found that problem smartphone use in general is predicted by younger age (Lu et al., 2011; van Deursen et al., 2015) and female gender (Jeong, Kim, Yum, \& Hwang, 2016; Wang et al., 2015). In contrast to van Deursen et al. (2015) who found that younger people engage in more process and social smartphone usage, we did not find such an effect for age; though we should note that age would be significant for process use at the alpha $<.05$ level, but not at our more stringent alpha $<.01$ level. Our findings are consistent with prior research finding that women engage in more social smartphone use than men do (van Deursen et al., 2015).

Our findings have theoretical, societal and clinical implications. Traditional theoretical models have examined psychopathology predicting increased smartphone use frequency, which in turn predicts problematic smartphone use (Elhai, Levine, et al., 2017; Kim, Seo, \& David, 2015; van Deursen et al., 2015). This model assumes that psychopathology lends itself to increase smartphone use, which in turn can grow into problematic 
use, a notion that fits with UGT (Blumler, 1979) and CIUT (Kardefelt-Winther, 2014). However, such models have rarely measured smartphone use frequency or problematic use in a multidimensional manner (using subscales), and future work could benefit from such a richer multidimensional approach. Clinically, mental health providers could inquire about their patients' smartphone use in order to obtain more information about patient daily behavioral activity; clinicians may not normally think to inquire about this issue. Additionally, because of the mental health benefits of social support (Kawachi \& Berkman, 2001), and the social support/social capital advantages from smartphones (Park et al., 2012), social smartphone use could be beneficial to patient mental health. Finally, problematic smartphone use could also be assessed using a measure such as the SAS, in order to capture additional, standardized clinical data.

Limitations in this study include that we did not objectively assess smartphone behavior, but rather used selfreport methods. We used a community sample of Mturk participants, and such sampling may not be representative of the general population, with Mturk participants being younger and more technologically savvy (Shapiro, Chandler, \& Mueller, 2013). Additionally, given the small amount of variance accounted for in social smartphone use, other predictive factors that were not examined in this paper may play a role in such use. For example, personality trait constructs (Elhai, Levine, Dvorak, \& Hall, 2016; Elhai, Levine, et al., 2017), emotional gain (Zhitomirsky-Geffet \& Blau, 2016) and social stress (van Deursen et al., 2015) may be important. Nonetheless, findings provide insight into the types of problem smartphone behaviors associated with specific uses and gratifications from a smartphone.

\section{Author Disclosure}

The authors report no competing financial interests.

\section{References}

Blumler, J. G. (1979). The role of theory in uses and gratifications studies. Communication Research, 6, 9-36. https://doi.org/10.1177/009365027900600102

Blumler, J. G., \& Katz, E. (1974). The uses of mass communications: Current perspectives on gratifications research. Beverly Hills, California: Sage.

Cazzulino, F., Burke, R. V., Muller, V., Arbogast, H., \& Upperman, J. S. (2014). Cell phones and young drivers: A systematic review regarding the association between psychological factors and prevention. Traffic Injury Prevention, 15, 234-242. https://doi.org/10.1080/15389588.2013.8222075

Chou, C., \& Hsiao, M.-C. (2000). Internet addiction, usage, gratification, and pleasure experience: The Taiwan college students' case. Computers \& Education, 35, 65-80. https://doi.org/10.1016/S0360-1315(00)00019-1

Demirci, K., Akgonul, M., \& Akpinar, A. (2015). Relationship of smartphone use severity with sleep quality, depression, and anxiety in university students. Journal of Behavioral Addictions, 4, 85-92.

https://doi.org/10.1556/2006.4.2015.010

Dhir, A., Chen, S., \& Nieminen, M. (2015). Predicting adolescent Internet addiction: The roles of demographics, technology accessibility, unwillingness to communicate and sought Internet gratifications. Computers in Human Behavior, 51, 24-33. https://doi.org/10.1016/j.chb.2015.04.056

Elhai, J. D., Dvorak, R. D., Levine, J. C., \& Hall, B. J. (2017). Problematic smartphone use: A conceptual overview and systematic review of relations with anxiety and depression psychopathology. Journal of Affective Disorders, 207, 251-259. https://doi.org/10.1016/j.jad.2016.08.030

Elhai, J. D., Levine, J. C., Dvorak, R. D., \& Hall, B. J. (2016). Fear of missing out, need for touch, anxiety and depression are related to problematic smartphone use. Computers in Human Behavior, 63, 509-516. https://doi.org/10.1016/j.chb.2016.05.079

Elhai, J. D., Levine, J. C., Dvorak, R. D., \& Hall, B. J. (2017). Non-social features of smartphone use are most related to depression, anxiety and problematic smartphone use. Computers in Human Behavior, 69, 75-82.

https://doi.org/10.1016/j.chb.2016.12.023 
Eyvazlou, M., Zarei, E., Rahimi, A., \& Abazari, M. (2016). Association between overuse of mobile phones on quality of sleep and general health among occupational health and safety students. Chronobiology International, 33, 293300. https://doi.org/10.3109/07420528.2015.1135933

Godwin-Jones, R. (2011). Mobile apps for language learning. Language Learning and Technology, 15(2), 2-11.

Gunuc, S. (2015). Relationships and associations between video game and Internet addictions: Is tolerance a symptom seen in all conditions. Computers in Human Behavior, 49, 517-525.

https://doi.org/10.1016/j.chb.2015.03.063

Jeong, S.-H., Kim, H., Yum, J.-Y., \& Hwang, Y. (2016). What type of content are smartphone users addicted to?: SNS vs. games. Computers in Human Behavior, 54, 10-17. https://doi.org/10.1016/j.chb.2015.07.035

Kalkbrenner, J., \& McCampbell, A. (2011). The advent of smartphones: A study on the effect of handheld electronics on personal and professional productivity. Journal of Applied Global Research, 4, 1-9.

Kardefelt-Winther, D. (2014). A conceptual and methodological critique of internet addiction research: Towards a model of compensatory internet use. Computers in Human Behavior, 31, 351-354.

https://doi.org/10.1016/j.chb.2013.10.059

Kawachi, I., \& Berkman, L. F. (2001). Social ties and mental health. Journal of Urban Health, 78, 458-467. https://doi.org/10.1093/jurban/78.3.458

Kim, J., \& Haridakis, P. M. (2009). The role of internet user characteristics and motives in explaining three dimensions of internet addiction. Journal of Computer-Mediated Communication, 14, 988-1015.

https://doi.org/10.1111/j.1083-6101.2009.01478.x

Kim, J., Seo, M., \& David, P. (2015). Alleviating depression only to become problematic mobile phone users: Can face-to-face communication be the antidote? Computers in Human Behavior, 51, 440-447.

https://doi.org/10.1016/j.chb.2015.05.030

Kuss, D. J., Griffiths, M. D., \& Binder, J. F. (2013). Internet addiction in students: Prevalence and risk factors. Computers in Human Behavior, 29, 959-966. https://doi.org/10.1016/j.chb.2012.12.024

Kwon, M., Lee, J. Y., Won, W. Y., Park, J. W., Min, J. A., Hahn, C., . . Kim, D. J. (2013). Development and validation of a smartphone addiction scale (SAS). PLoS One, 8(2), e56936. https://doi.org/10.1371/journal.pone.0056936

Lee, U., Song, J., Lee, J., Ko, M., Lee, C., Kim, Y., . . Chung, K.-M. (2014, April). Hooked on smartphones: An exploratory study on smartphone overuse among college students. Paper presented at the Proceedings of the SIGCHI Conference on Human Factors in Computing Systems, Toronto, Ontario. Retrieved from http://koasas.kaist.ac.kr/bitstream/10203/191367/1/81485.pdf

Long, J., Liu, T. Q., Liao, Y. H., Qi, C., He, H. Y., Chen, S. B., \& Billieux, J. (2016). Prevalence and correlates of problematic smartphone use in a large random sample of Chinese undergraduates. BMC Psychiatry, 16, 408. https://doi.org/10.1186/s12888-016-1083-3

Lopez-Fernandez, O., Honrubia-Serrano, L., Freixa-Blanxart, M., \& Gibson, W. (2014). Prevalence of problematic mobile phone use in British adolescents. Cyberpsychology, Behavior, and Social Networking, 17, 91-98.

https://doi.org/10.1089/cyber.2012.0260

Lu, X., Watanabe, J., Liu, Q., Uji, M., Shono, M., \& Kitamura, T. (2011). Internet and mobile phone text-messaging dependency: Factor structure and correlation with dysphoric mood among Japanese adults. Computers in Human Behavior, 27, 1702-1709. https://doi.org/10.1016/j.chb.2011.02.009

Oulasvirta, A., Rattenbury, T., Ma, L., \& Raita, E. (2012). Habits make smartphone use more pervasive. Personal and Ubiquitous Computing, 16, 105-114. https://doi.org/10.1007/s00779-011-0412-2

Ozdalga, E., Ozdalga, A., \& Ahuja, N. (2012). The smartphone in medicine: A review of current and potential use among physicians and students. Journal of Medical Internet Research, 14(5), e128. https://doi.org/10.2196/jmir

Park, K. G., Han, S., \& Kaid, L. L. (2012). Does social networking service usage mediate the association between smartphone usage and social capital? New Media \& Society, 15, 1077-1093.

https://doi.org/10.1177/1461444812465927 
Park, N., Kim, Y.-C., Shon, H. Y., \& Shim, H. (2013). Factors influencing smartphone use and dependency in South Korea. Computers in Human Behavior, 29, 1763-1770. https://doi.org/10.1016/j.chb.2013.02.008

Rebold, M. J., Sheehan, T., Dirlam, M., Maldonado, T., \& O'Donnell, D. (2016). The impact of cell phone texting on the amount of time spent exercising at different intensities. Computers in Human Behavior, 55, 167-171. https://doi.org/10.1016/j.chb.2015.09.005

Robinson, T. E., \& Berridge, K. C. (2000). The psychology and neurobiology of addiction: An incentive-sensitization view. Addiction, 95(Suppl2), S91-S117. https://doi.org/10.1080/09652140050111681

Rozgonjuk, D., Rosenvald, V., Janno, S., \& Täht, K. (2016). Developing a shorter version of the Estonian Smartphone Addiction Proneness Scale (E-SAPS18). Cyberpsychology: Journal of Psychosocial Research on Cyberspace, 10(4), article 4. https://doi.org/10.5817/cp2016-4-4

Seo, D. G., Park, Y., Kim, M. K., \& Park, J. (2016). Mobile phone dependency and its impacts on adolescents' social and academic behaviors. Computers in Human Behavior, 63, 282-292. https://doi.org/10.1016/j.chb.2016.05.026

Shan, Z., Deng, G., Li, J., Li, Y., Zhang, Y., \& Zhao, Q. (2013). Correlational analysis of neck/shoulder pain and low back pain with the use of digital products, physical activity and psychological status among adolescents in Shanghai. PLoS One, 8(10), e78109. https://doi.org/10.1371/journal.pone.0078109

Shapiro, D. N., Chandler, J., \& Mueller, P. A. (2013). Using Mechanical Turk to study clinical populations. Clinical Psychological Science, 1, 213-220. https://doi.org/10.1177/2167702612469015

Song, I., LaRose, R., Eastin, M. S., \& Lin, C. A. (2004). Internet gratifications and Internet addiction: On the uses and abuses of new media. Cyberpsychology, Behavior, and Social Networking, 7, 384-394.

https://doi.org/10.1089/cpb.2004.7.384

Steelman, Z. R., Hammer, B. I., \& Limayem, M. (2014). Data collection in the digital age: Innovative alternatives to student samples. MIS Quarterly, 38, 355-378.

Thompson, L. L., Rivara, F. P., Ayyagari, R. C., \& Ebel, B. E. (2013). Impact of social and technological distraction on pedestrian crossing behaviour: An observational study. Injury Prevention, 19, 232-237.

https://doi.org/10.1136/injuryprev-2012-040601

Trepte, S., Reinecke, L., \& Juechems, K. (2012). The social side of gaming: How playing online computer games creates online and offline social support. Computers in Human Behavior, 28, 832-839.

https://doi.org/10.1016/j.chb.2011.12.003

van Deursen, A. J. A. M., Bolle, C. L., Hegner, S. M., \& Kommers, P. A. M. (2015). Modeling habitual and addictive smartphone behavior: The role of smartphone usage types, emotional intelligence, social stress, self-regulation, age, and gender. Computers in Human Behavior, 45, 411-420. https://doi.org/10.1016/j.chb.2014.12.039

Wang, Z., Tchernev, J. M., \& Solloway, T. (2012). A dynamic longitudinal examination of social media use, needs, and gratifications among college students. Computers in Human Behavior, 28, 1829-1839.

https://doi.org/10.1016/j.chb.2012.05.001

Wang, J.-L., Wang, H.-Z., Gaskin, J., \& Wang, L.-H. (2015). The role of stress and motivation in problematic smartphone use among college students. Computers in Human Behavior, 53, 181-188. https://doi.org/10.1016/j.chb.2015.07.005

West, R., \& Turner, L. (2007). Introducing communication theory. New York City, New York: McGraw Hill.

Wise, R. A., \& Koob, G. F. (2014). The development and maintenance of drug addiction.

Neuropsychopharmacology, 39, 254-262. https://doi.org/10.1038/npp.2013.261

Xie, Y., Szeto, G. P., Dai, J., \& Madeleine, P. (2016). A comparison of muscle activity in using touchscreen smartphone among young people with and without chronic neck-shoulder pain. Ergonomics, 59, 61-72. https://doi.org/10.1080/00140139.2015.1056237

Yang, S. C., \& Tung, C.-J. (2007). Comparison of Internet addicts and non-addicts in Taiwanese high school. Computers in Human Behavior, 23, 79-96. https://doi.org/10.1016/j.chb.2004.03.037 
Zhitomirsky-Geffet, M., \& Blau, M. (2016). Cross-generational analysis of predictive factors of addictive behavior in smartphone usage. Computers in Human Behavior, 64, 682-693. https://doi.org/10.1016/j.chb.2016.07.061

\author{
Correspondence to: \\ Brian Hall \\ Department of Psychology \\ University of Macau \\ Av. da Universidade \\ Taipa, Macau \\ China \\ E-mail: brianhall(at)umac.mo
}

\begin{abstract}
About Authors
Jon D. Elhai is Professor of Psychology and Psychiatry at the University of Toledo. His primary area of research is in posttraumatic stress disorder (PTSD), examining assessment, diagnostic, comorbidity and mechanistic issues in PTSD. He also has a program of research on the impact of computer technology on human behavior, examining anxiety about internet hacking and information privacy, protecting one's online data and electronic communications, and problematic internet and smartphone use.
\end{abstract}

Brian J. Hall is Director of the Global and Community Mental Health Research Group and Assistant Professor of Psychology at University of Macau, People's Republic of China. His research focuses on social determinants of population health, consequences of adversity and traumatic stress, and evaluating intervention programs for marginalized populations in China.

Jason C. Levine is Assistant Professor of Psychology and Psychiatry at the University of Toledo. He researches generalized anxiety disorder, cardiovascular psychophysiology, psychotherapy process and outcomes.

Robert D. Dvorak is Assistant Professor of Psychology at the University of Central Florida. He researches health risk behaviors through the lens of cognitive, emotional and behavioral self-regulation.

Editorial record: First submission received on August 12, 2016. Revision received on February 1, 2017. Accepted for publication on March 23, 2017. 